\title{
Linear Fresnel Lens Optimization for Middle Concentrated Photovoltaic
}

\author{
Je Heon Song ${ }^{1}$, Jin Hee Yu', Jun Ho Lee ${ }^{1 \dagger}$, Won Keun Jang ${ }^{2}$, and Dong Gil Lee ${ }^{2}$ \\ ${ }^{1}$ Geometrical Optics Lab., Kongju National University, 56 Kongjudaehak-ro, Kongju 314-701, Korea \\ ${ }^{2} 3 D$ Convergence Technology Research Center, Korea Photonics Technology Institute, Cheomdan Venture-ro, \\ 108 Beon-gil, Buk-gu, Gwangju 500-779, Korea
}

(Received July 30, 2013; Revised manuscript September 12, 2013; Accepted October 4 2013)

\begin{abstract}
This paper presents a combination of linear Fresnel lenses optimized for $\times 25$ solar concentration. The combined lens consists of $5 \times 5$ linear Fresnel lenses. Each Fresnel lens is of $10 \times 10 \mathrm{~mm}$ and optimized to tilt the incoming light onto a solar cell of the same size. All of the optimized Fresnel segments have the same pattern height of $35 \mu \mathrm{m}$, draft angle of $4^{\circ}$, and edge groove round of $1 \mu \mathrm{m}$ but with different facet angles varying from $14.1^{\circ}$ to $31.2^{\circ}$. The solar concentrating efficiency of the combination is shown to be over $80 \%$ and more robust than a conventional single $\times 25$ circular Fresnel lens in terms of pointing misalignment and manufacturing errors. A sensitivity analysis finds that the edge groove round should be kept as small as machining allows since the concentrating efficiency drops $\sim 5 \%$ per $1 \mu \mathrm{m}$ increase of the edge groove.
\end{abstract}

Keywords: Linear Fresnel lens, Lens optimization, Concentrated Photovoltaic (CPV)

OCIS codes: (080.0080) Geometric optics; (080.2740) Geometric optical design; (080.3630) Lenses; (350.6050) Solar energy

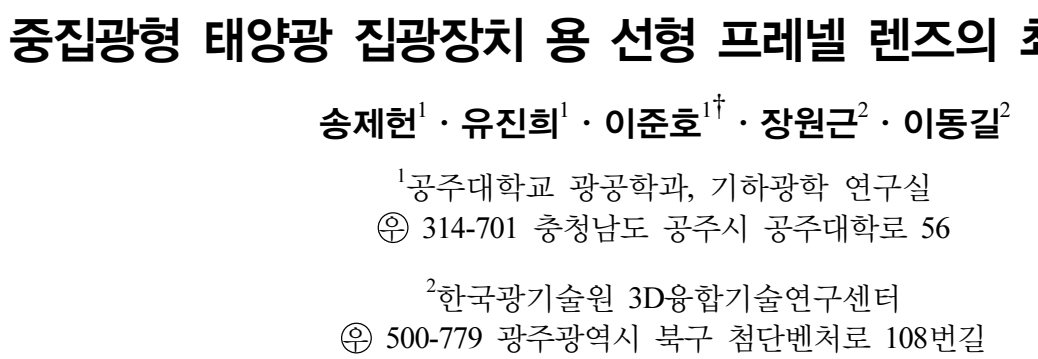

(2013년 7월 30일 받음, 2013년 9월 12일 수정본 받음, 2013년 10월 4일 게재 확정)

본 논문에서는 25 배 태양광 집광장치에 적용될 선형 프레넬 렌즈의 최적화에 대해 서술한다. 이 선형 프레넬 렌즈는 각기 다른 패턴을 가진 $10 \times 10 \mathrm{~mm}$ 크기의 선형 프레넬 렌즈가 $5 \times 5$ 의 형태로 결합된 렌즈이다. 각 프레넬 렌즈는 같은 크기의 태양전지로 태양광이 입사할 수 있도록 최적화되어 있다. 최적화된 프레넬 렌즈의 설계치는 패턴높이 $35 \mu \mathrm{m}$, 구배각 $4^{\circ}$, 모서리 라운드 1 $\mu \mathrm{m}$ 로 각각의 선형 프레넬 렌즈에 모두 같은 값이 부여되었지만 사면경사각은 $14.1^{\circ} \sim 31.2^{\circ}$ 로 각기 다르다. 이렇게 설계된 선형 프레넬 렌즈의 태양광 집광효율은 $80 \%$ 이상이며 기존의 25 배 집광용 단일 프레넬 렌즈보다 오정렬 및 제작공차 측면에서 강력한 성능을 가진다. 설계된 선형 프레넬 렌즈의 민감도 분석을 통해 모서리 라운드가 $1 \mu \mathrm{m}$ 씩 증가할수록 집광효율이 5\%씩 저하되 는 것을 파악하였고 이에 모서리 라운드가 최소한의 수치로 유지되어야 함을 확인하였다.

Keywords: 선형 프레넬 렌즈, 최적화, 중집광형 태양광 집광장치

OCIS codes: (080.0080) Geometric optics; (080.2740) Geometric optical design; (080.3630) Lenses; (350.6050) Solar energy

\section{I. 서 론}

세계적인 에너지 수요는 해마다 점차 증가하여 2050년에 는 지금의 두 배 이상 그리고 21 세기 말에는 지금의 세 배
이상 증가할 것으로 예상하고 있다. ${ }^{[1]}$ 그러나 지금의 에너지 원으로는 증가하는 수요를 따라잡기 어려워 이미 세계 여러 나라에서는 대체 에너지원의 개발에 총력을 기울이고 있다. 친환경적인 에너지 개발 측면에서 태양광은 기존의 에너지

\footnotetext{
${ }^{\dagger}$ E-mail: jhlsat@kongju.ac.kr

Color versions of one or more of the figures in this paper are available online.
} 
원을 대체할 수 있는 좋은 에너지원이다. ${ }^{[2]}$ 태양광 에너지 기 술은 태양광을 집광하여 사용하는 방법과 태양열을 이용하 는 방법으로 나눌 수 있으며 본 연구에서는 집광형 태양광 발전장치를 다루고자 한다.

현재 사용되고 있는 태양광 발전장치는 태양광이 입사하는 면적만큼 태양전지를 배치하여 태양광 에너지를 집적하여 발전하는 방식이다. 이런 방식의 태양광 발전장치는 고가의 태양전지를 대면적으로 사용하는 방식으로, 태양광 발전장치 의 제작비용을 증가시켜 결과적으로는 발전 단가의 비싼 가 격으로 인해 대중화되지 못하여 최근에는 광학렌즈를 이용 한 태양광 집광장치가 연구되고 있다. ${ }^{[3]}$ 태양광 집광장치는 넓은 면적으로 입사하는 태양광을 좁은 면적의 태양전지에 모아 사용하도록 하여 값비싼 태양전지의 면적을 최소화 하 면서도 넓은 면적으로 입사하는 태양광 에너지를 최대한으 로 사용할 수 있게 하여 태양광 에너지의 효율을 극대화 하 면서도 비용은 획기적으로 줄일 수 있게 한다. ${ }^{[2]}$

태양광 집광장치는 통상적으로 집광배율에 따라 1 10배율 의 저집광형, $10 \sim 100$ 배율의 중집광형, 100 배율 이상의 고집 광형으로 분류되는데 고집광형 태양광 집광장치는 집광율이 높은 반면 태양전지의 온도상승에 의한 효율저하 및 이에 따 른 냉각장치 추가에 의한 비용상승이 우려되고 또한 높은 민 감도를 가지게 되어 태양광 입사각의 정밀한 제어가 필요하 고 이에 따른 정밀 추적장치의 사용에 의해 제작비용이 증가 하게 된다. ${ }^{[1]}$ 저집광형 태양광 집광장치는 민감도가 낮고 열 에 의한 문제가 야기되지 않는 반면 집광율이 낮은 단점이 있다. 이에 본 연구에서는 집광에 의한 열화현상으로 인한 손상의 우려가 없고 2 차렌즈를 사용하지 않는 선형 프레넬 렌즈로 집광렌즈를 설계하였다. ${ }^{[4]}$

선형 프레넬 렌즈를 사용하는 태양광 집광장치는 여러 분 야에서 연구된 바 있으나 선행 연구된 부분은 선형 프레넬 렌즈의 설계변수와 렌즈에 의한 집광효율이 계산되는 방식 등이다. 본 논문에서는 선형 프레넬 렌즈를 사용한 태양광 집광렌즈를 설계하고 이 렌즈의 가공정밀도가 집광효율에 미치는 영향을 살펴보고 집광효율의 저하에 중대한 영향을 미치는 설계변수를 미리 파악하여 관리할 수 있도록 하여 결 과적으로 집광렌즈의 효율을 극대화할 수 있도록 최적화 설 계연구를 진행하였다.

\section{II. 선형 프레넬 렌즈 설계}

집광렌즈는 돋보기처럼 렌즈전면으로 입사하는 태양광을 좁은 면적의 태양전지에 모아주는 역할을 하는데 이때 집광 렌즈는 굴절효과는 그대로 유지하면서 두께와 무게를 최소 화하기 위해 프레넬 렌즈로 설계한다. 프레넬 렌즈는 일반적 으로 원형 프레넬 렌즈와 선형 프레넬 렌즈로 구분되며 원형 프레넬 렌즈로 설계할 경우 태양광이 원형으로 집광되므로 태양전지의 전면을 고루 사용할 수 없어 태양전지의 효율이 저하된다.

이 단점을 해소하기 위해서는 사각형의 태양전지에 균일하
게 에너지를 분포시키기 위한 2 차 렌즈가 반드시 필요하게 되는데 ${ }^{[5]}$ 집광장치에 2 차렌즈를 추가할 경우 집광장치의 두 께가 현저히 증가하게 되고 이는 제작비용의 증가로 직결된 다. ${ }^{[3]}$ 하여 본 연구에서는 태양광 집광장치에 사용되는 집광 렌즈를 태양광이 직접 면으로 집광될 수 있도록 설계하는 것 이 가능하여 부가적인 광학계의 사용이 불필요하고 이에 따 른 제작비용 감소가 가능한 장점이 있는 선형 프레넬 렌즈로 집광렌즈를 설계하였다.

기본적인 설계의 개념은 $10 \times 10 \mathrm{~mm}$ 크기의 선형 프레넬 렌즈 여러 개가 정사각의 타일형태로 배치되도록 하고 각각 의 렌즈를 통과한 태양광이 $10 \times 10 \mathrm{~mm}$ 크기의 태양전지에 1 대 1 로 전달되어 집광되는 방식으로 선형 프레넬 렌즈의 개 수가 집광렌즈의 집광배율을 결정하도록 하는 것이다. 그림 1 은 다수의 선형 프레넬 렌즈를 사용하는 집광렌즈의 설계 개념을 보여주고 있다.

다수의 선형 프레넬 렌즈를 결합하여 사용할 경우 기존의 단일 프레넬 렌즈를 사용할 때보다 오정렬 및 제작공차 측면 에서 더욱 강력한 성능을 갖는다. 단일 프레넬 렌즈를 사용

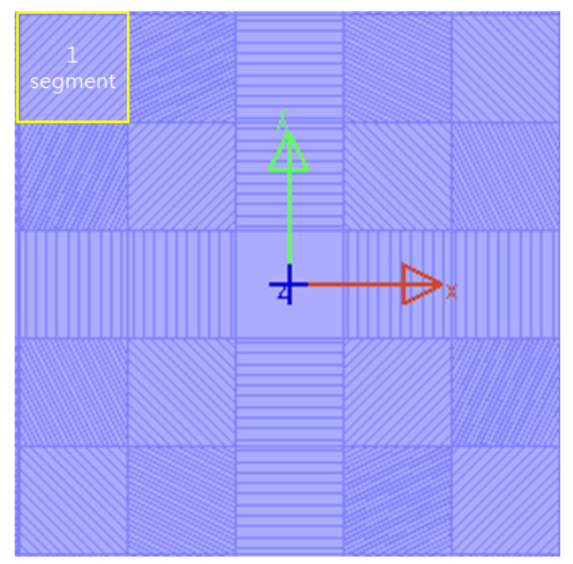

(a)

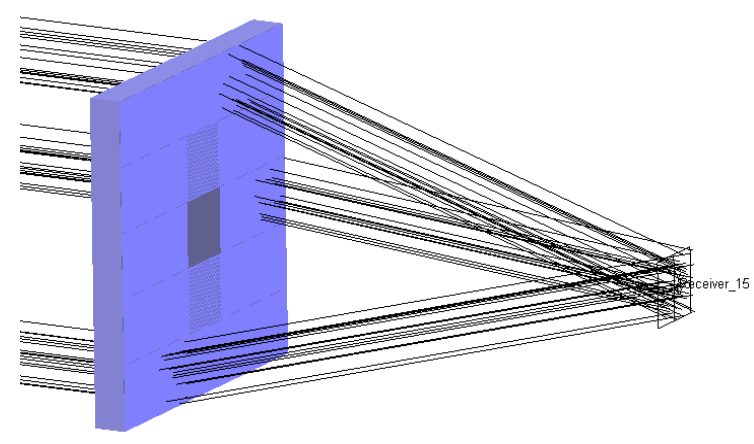

(b)

FIG. 1. Design concept of linear Fresnel lens for $\times 25$ solar concentration. (a) top view of the linear Fresnel lens. (b) three dimensional view. 


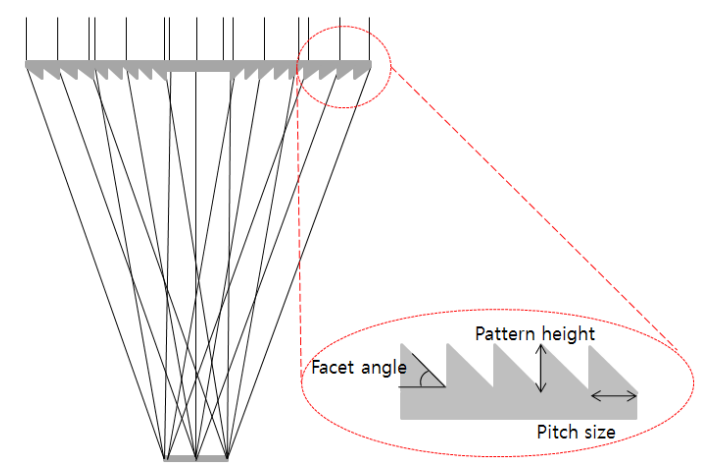

FIG. 2. Design parameters of linear Fresnel lens.

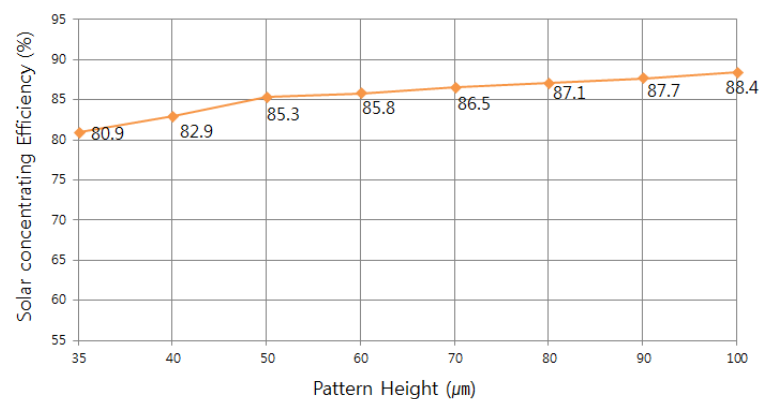

FIG. 3. Solar concentrating efficiency (\%) as the pattern height variation from 5 to $100 \mu \mathrm{m}$.

할 경우 태양광이 입사하는 각도에 따라 태양전지에 집광되 는 에너지의 효율이 급격하게 달라져서 태양의 각도에 따라 발전장치의 각도를 바꿔주는 부가적인 장치가 필요하게 된 다. ${ }^{[6]}$ 하지만 다수의 선형 프레넬 렌즈를 결합하여 사용할 경 우 태양광 입사각에 의한 민감도가 상대적으로 낮아져 태양 의 각도에 의한 변화에 대처하기 위한 부가적인 장치 없이도 효율적인 태양광 발전이 가능하다.

각각의 선형 프레넬 렌즈가 1 개의 태양전지로 태양광을 전 달하기 위해서는 렌즈를 각각 설계하여 종합하는 방식으로 구현할 수 있다. 프레넬 렌즈의 설계방식은 크게 두 가지로 구분할 수 있는데 첫째로는 패턴의 높이(Pattern height)를 일 정하게 고정하고 사면경사각(Facet angle)을 변경하기 위해서 피치사이즈(Pitch size)를 바꾸는 방식이고 두 번째는 피치사 이즈를 고정하고 패턴의 높이를 변화시켜 사면경사각을 정 하는 방식이다. 두 가지 방식 중 설계하고자 하는 프레넬 렌 즈에 적합한 방식을 선택하여 설계할 수 있는데 본 연구에서 는 패턴의 높이를 일정하게 고정한 뒤 피치사이즈를 바꾸어 사면경사각을 조절하는 방식의 설계를 채택하였다. 각 선형 프레넬 렌즈를 설계하기 위한 설계요소는 그림 2 와 같다.

사면경사각은 프레넬 렌즈를 통과한 태양광이 태양전지로 입사되도록 하기 위해 필요한 굴절각도이며 패턴각도(Pattern angle)는 집광렌즈의 중심인 광축으로부터 해당 선형 프레넬 렌즈 타일의 중심점을 이어 구한 각도로 각각의 선형 프레넬 렌즈를 통과한 태양광이 광축에 위치한 태양전지로 입사되 도록 프레넬 렌즈의 패턴을 회전시키는 각도 ${ }^{[7]}$ 로, 그림 4 에
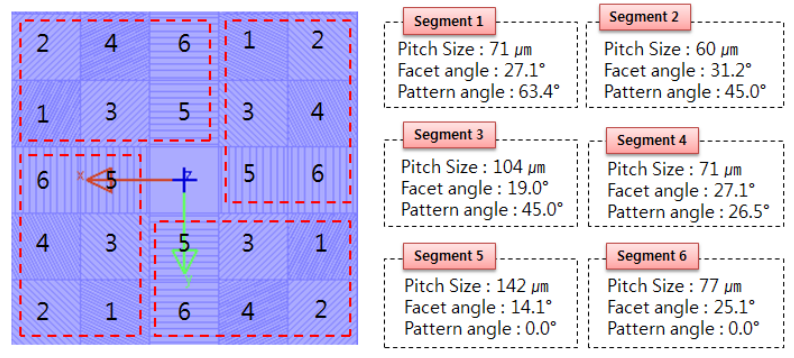

FIG. 4. Each segments design value for optimized $\times 25$ linear Fresnel lens.

나타내었다.

설계요소 중 패턴의 높이는 집광렌즈의 효율에 크게 영향 을 미치는 설계요소이므로 패턴높이에 따른 효율 저하에 대 해 분석을 진행하였다. 여기에서 효율은 집광렌즈에 1 watt 의 빛이 입사했을 때 태양전지에서 검출된 빛을 분석하여 구 한 값으로, 렌즈의 투과율은 $98 \%$ 라고 가정하였다. 그림 3은 패턴의 높이의 변화에 의한 효율 저하를 분석한 결과로, 그 림 3에서 알 수 있듯이 프레넬 렌즈의 패턴의 높이가 높을수 록 집광렌즈의 집광효율이 좋아진다. 하지만 제작상의 이유 로 패턴의 높이는 무한대로 높아질 수 없고 제작사에서 패턴 높이에 대한 구속조건을 제시하여 그에 따라 제작이 가능한 범위 내에서 최대한의 패턴높이를 설계에 반영하였다.

이와 같은 설계요소를 반영한 선형 프레넬 렌즈의 최종설 계치는 그림 4 에 나타내었다.

초기설계에서는 제작공차에 해당하는 모서리 라운드(Edge groove round)와 구배각(Draft angle)을 0 으로 설계하여 이상 적인 프레넬 렌즈를 설계하고 이때 집광렌즈로 입사한 광량 대비 태양전지에서 검출된 광량을 분석한 뒤 계산하여 집광 렌즈의 효율을 계산하였다.

이렇게 이상적인 프레넬 렌즈로 설계된 집광렌즈는 패턴의 높이가 $35 \mu \mathrm{m}$ 일 때 $85 \%$ 가량의 효율을 갖는다. 하지만 실 제 제작 시에는 이와 같이 이상적인 프레넬 렌즈를 제작할 수 없으므로 현실적으로 제작 가능하도록 허용 가능한 오차 를 포함한 설계를 실시하였다.

\section{III. 민감도분석}

선형 프레넬 렌즈의 제작 시 오차가 발생할 가능성이 있는 설계요소에 대한 민감도분석을 실시하여 각 설계요소의 오 차가 렌즈의 성능인 집광효율에 미치는 영향을 파악한 뒤 제 작사와 논의를 통하여 제작 가능한 오차범위를 구하고 그 오 차범위 내에서 성능을 심각하게 저하시키지 않도록 초기 설 계값에 가공 오차를 포함하여 성능분석을 실시하였다. 먼저 제작사로부터 제작 가능한 최소한의 오차가 주어지면 이를 설계에 반영하여 성능이 저하되는 양상을 분석하고 이를 통 해 제작사로부터 전달받은 오차가 허용가능한지 여부를 판 단하였다. 표 1은 선형 프레넬 렌즈 제작 시 발생할 수 있는 설계변수의 오차부분에 대하여 집광렌즈 제작사로부터 전달 
받은 가공정밀도 정보를 나타내고 있다.

민감도 분석은 구배각에 따른 효율저하와 모서리 라운드에 따른 효율저하에 대해 진행하였다. 그림 5는 구배각에 대한 민감도 분석결과를 나타낸다. 표 1 에서와 같이 제작사에서 가공 가능한 구배각의 범위를 지정하면 초기설계 당시 0 으 로 설정되어 있었던 구배각이 증가함에 따라 집광효율이 저 하되는 양상을 파악하였다. 그림 5에서 볼 수 있듯이 구배각 증가에 의한 집광효율의 변화는 비교적 민감하지 않다. 이 결과에 따라 설계에 반영한 구배각은 $4^{\circ}$ 이며 이는 제작 시 발생할 수 있는 최악의 가공오차이고 $4^{\circ}$ 이내로 구배각을 가 공한다면 선형 프레넬 렌즈의 집광성능에 큰 저하는 없을 것 으로 판단된다.

또 다른 민감도 분석은 모서리 라운드에 대해 진행하였다. 모서리 라운드는 기계로 렌즈를 가공할 때 필연적으로 발생 하는 성능저하 요인으로 렌즈를 가공하는 기계의 크기에 의 해 발생한다. 그림 6 은 모서리 라운드의 증가에 의한 집광효

TABLE 1. Tolerance description

\begin{tabular}{l|c|c|c}
\hline & Description & Min & Max \\
\hline \multirow{2}{*}{$\begin{array}{c}\text { Edge } \\
\text { graft angle }\end{array}$} & &
\end{tabular}

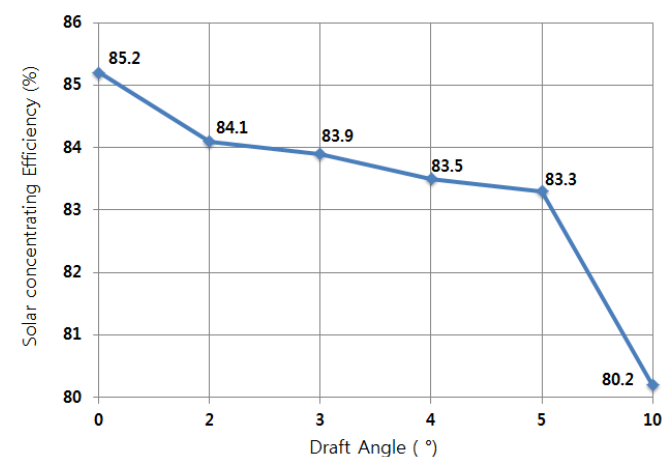

FIG. 5. Solar concentrating efficiency drops with increase in the draft angle.

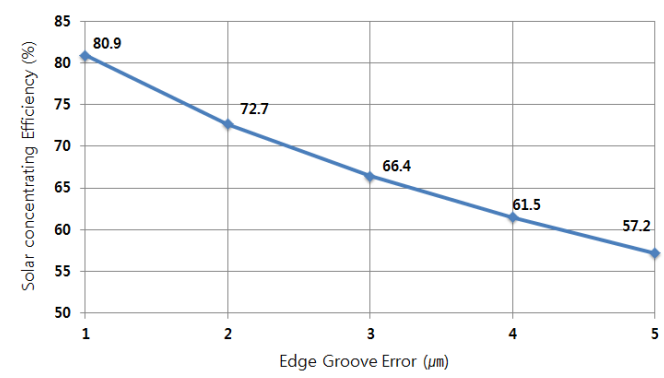

FIG. 6. Solar concentrating efficiency drops with increase in the edge groove error.
율 저하를 나타내었다.

그림 6 에서 모서리 라운드의 증가에 의한 성능저하는 다른 설계요소에 의한 성능저하보다 비교적 민감하여 $1 \mu \mathrm{m}$ 씩 점 차 에러가 증가할수록 집광효율의 저하가 급격하게 진행됨 을 알 수 있다. 그러므로 이 요소는 극소의 수치로 관리되어 야 한다고 판단하였고 제작사와 논의를 통하여 최종설계에 $1 \mu \mathrm{m}$ 의 모서리 라운드를 적용하였다.

\section{IV. 결 론}

태양광 집광장치에 사용되는 집광렌즈를 선형 프레넬 렌즈 로 설계하고 이에 대한 민감도분석을 실시하여 제작 가능한 범위 내에서 최고의 집광효율을 갖도록 최적화 설계를 실시 하였다. $35 \mu \mathrm{m}$ 의 패턴높이를 갖는 선형 프레넬 렌즈를 이용 한 집광렌즈는 $80 \%$ 이상의 효율을 가지며 이 집광렌즈는 현 재 가공이 진행 중에 있다. 가공이 완료되면 실제적인 측정 을 통하여 본 연구에서 실시한 최적화 설계연구의 타당성을 확인할 수 있을 것이다.

\section{감사의 말}

이 논문은 2012년도 지식경제부의 재원으로 한국에너지기 술평가관리원의 지원을 받아 수행한 연구결과입니다(No. 2012 3010010120).

\section{References}

1. K. H. Do, T. H. Kim, B. I. Choi, Y. S. Han, and M. B. Kim, "Development of a cooling system for a concentrating photovoltaic module," J. Korean Soc. Mech. Eng. 35, 174181 (2010).

2. K. S. Kim, G. H. Kang, and G. J. Yu, "The status paper on concentration photovoltaic system," J. Korean Solar Energy Soc. 14, 21-24 (2008).

3. K. S. Ryu, G. H. Shin, W. H. Cha, N. H. Myong, Y. S. Kim, H. Y. Chung, D. K. Kim, and G. H. Kang, "Simulation of characteristics of lens and light pipe for high concentration solar PV system," J. Korean Solar Energy Soc. 31, 282-286 (2008).

4. S. W. Kang, Y. S. Kim, and C. H. Sim, "Fresnel lens optics simulation with middle sized linear concentration without secondary optics," J. Korean Solar Energy Soc. 24, 27-33 (2011).

5. S. W. Kang, Y. S. Kim, and C. H. Sim, "PV receiver raytracing simulation with secondary optics in the CPV (Concentrated PV) system," J. Korean Solar Energy Soc. 30, 323-330 (2010).

6. P. Benitez, "High performance Fresnel-based photovoltaic concentrator," Opt. Express 18, A25-A40 (2010).

7. K. S. Ryu, "Concept and design of modular Fresnel lenses for concentration solar PV system," Solar Energy 80, 1580-1587 (2006). 